\title{
MEMBACA KECENDERUNGAN PEMIKIRAN ISLAM GENERASI MILENIAL INDONESIA
}

\author{
Agus Iswanto \\ Peneliti pada Balai Penelitian dan Pengembangan Agama Semarang \\ agus.iswanto83@gmail.com \\ Artikel diterima 13 Juni, diseleksi 16 Juni, dan disetujui 25 Juni 2018
}

\begin{tabular}{|c|c|c|}
\hline Judul & : & $\begin{array}{l}\text { Literatur Keislaman Generasi Milenial: Transmisi, Aprosiasi dan } \\
\text { Kontestasi }\end{array}$ \\
\hline Penulis & : & $\begin{array}{l}\text { Noorhaidi Hasan, Suhadi, Munirul Ikhwan, Moch Nur Ichwan, } \\
\text { Najib Kailani, Ahmad Rafiq dan Ibnu Burdah }\end{array}$ \\
\hline Editor & : & Noorhaidi Hasan \\
\hline ISBN & : & $978-602-50682-4-9$ \\
\hline Tebal & : & xvi + 304 halaman \\
\hline Cetakan & : & Kedua, April 2018 \\
\hline Penerbit & : & Pascasarjana UIN Sunan Kalijaga Press \\
\hline
\end{tabular}

Indonesia akan mengalami apa yang disebut dengan "bonus demografi" di sekitar tahun 2020-2030. Berdasarkan prediksi Badan Kependudukan dan Keluarga Berencana Nasional (BKKBN), pada tahun-tahun tersebut, $70 \%$ warga Indonesia berada di usia produktif, yakni antara usia 15 hingga 64 tahun. Hanya sekitar $30 \%$ yang berusia tidak produktif, yakni mulai usia 14 tahun ke bawah dan 65 tahun ke atas.

Hal yang penting dicatat adalah, bonus demografi tersebut dapat meningkatkan jumlah anak muda, atau yang sekarang banyak disebut dengan generasi milenial. Untuk konteks Indonesia, gaya hidup anak muda milenial akan memiliki pengaruh yang besar terhadap berbagai aspek kehidupan, baik secara personal maupun publik, baik dari sisi sosial, budaya, hingga ekonomi, politik bahkan hingga agama. Melihat uraian tersebut, anak muda Muslim memiliki posisi yang strategis. Posisi strategis itu tidak hanya untuk konteks nasional, tetapi juga internasional. Muslim milenial dapat mengangkat citra Islam Indonesia agar menjadi rujukan dunia dalam mewujudkan masyarakat yang damai dan berkeadaban.
Namun, faktanya sekarang ini banyak narasi kebencian dan bahkan aksi kekerasan hingga teror dilakukan oleh anak-anak muda. Berita di media massa Indonesia baru-baru ini santer diberitakan beberapa anak muda sudah terpapar radikalisme bahkan bersedia melakukan aksi teror atas dasar keyakinan agama yang dianutnya. Sebagian kampus juga diduga terpapar radikalisme. Seakan fakta-fakta ini justru menunjukkan petaka bonus demografi.

Beberapa hasil penelitian pun menunjukkan gejala yang sama. Hasil penelitian Pusat Pengkajian Islam dan Masyarakat (PPIM) dan Center for the Study of Religion and Culture (CSRC) (Bamualim, dkk., 2018), yang menunjukkan generasi muda Muslim milenial terpelajar cenderung menganut sikap dan perilaku keberagamaan yang konservatif dengan coraknya yang komunal, skriptural, dan puritan.

Penelitian lainnya yang dilakukan oleh PPIM (2018) menemukan bahwa pada level opini, siswa/mahasiswayang merupakan generasi muda milenial Muslim Indonesia-cenderung memiliki pandangan keagamaan yang intoleran. 
Sedangkan dari sisi aksi, tampak bahwa siswa/mahasiswa memiliki perilaku keagamaan yang cenderung moderat/ toleran. Mereka yang termasuk dalam kategori aksi radikal, hanya 7.0\% dan aksi intoleransi eksternal $17.3 \%$. Namun pada aksi intoleransi internal, cenderung lebih tinggi, yaitu $34.1 \%$. Menurut penelitian tersebut, anak-anak muda ini memahami jihad sebagai perang (qital) dan terutama ditujukkan kepada non-Muslim.

Data seperti ini kemudian memicu pertanyaan, apa sesungguhnya yang menjadikan anak-anak muda ini cenderung pada konservatisme? Salah satu jawaban yang mengemuka adalah soal pembelajaran PAI yang diberikan oleh guru, dosen maupun mentor. Model pembelajaran Pendidikan Agama Islam (PAI) berpotensi membentuk radikalisme siswa. Sama halnya dengan opini radikal guru, model pembelajaran PAI dari guru juga bisa memengaruhi radikalisme siswa. Artinya, guru menjadi faktor penting dalam pembentukan seseorang dalam proses menjadi intoleran dan radikal (PPIM, 2018).

Jika memang guru dan model pembelajaran Pendidikan Agama Islam berpotensi membentuk radikalisme siswa, pertanyaan selanjutnya muncul adalah mengapa hal itu dapat terjadi? Dari mana guru atau dosen mendapatkan pengetahuan keagamaan yang kemudian diajarkan kepada siswa atau mahasiswanya? Belum lagi kenyataannya, anak-anak muda ini bukan generasi yang pasif hanya menerima pengetahuan dari sang guru, dosen atau mentor, mereka juga cenderung mencari pengetahuan keagamaan dari sumber-sumber lain yang lebih menarik menurut mereka. Sumber-sumber itulah yang kemudian disebut dengan literatur dalam beragam genre dan bentuknya.

Kualitas literatur menyumbang pada kualitas literasi atau pengetahuan agama mahasiswa (Hayik, 2015: 95;
Rackley, 2010: 107). Beberapa hasil studi juga menunjukkan bahwa teks atau literatur keagamaan memberikan 'pengaruh,' langsung atau tidak langsung, terhadap pemahaman keagamaan seseorang baik pada masa lalu maupun sekarang, bahkan wacana dan praktik keagamaan kontemporer terkadang tidak lepas dari teks-teks keagamaan yang diterima, dikutip serta dirujuk dalam pusaran wacana dan praktik keagamaan tersebut (Dhuhri, 2016; Watson, 2005: 177; Bowen, 1993; 5). Karena itu, studi terhadap literatur keagamaan penting sebagai sebuah upaya memetakan wacana keagamaan yang berkembang dalam masyarakat, termasuk di kalangan anak muda.

Buku Literatur Keislaman Generasi Milenial adalah salah ikhtiar pemetaan tersebut. Buku ini adalah bagian dari rangkaian riset keberagamaan anak muda yang dilakukan atas sponsor United Nations Development Program (UNDP) dengan PPIM UIN Jakarta dan Pascasarjana UIN Sunan Kalijaga Yogyakarta. Seperti dua riset yang telah disebutkan di atas (PPIM dan CSRC), riset ini diselenggarakan di bawah payung program CONVEY (Countering Violent Extermism for Youth). Proyek CONVEY Indonesia dimaksudkan untuk merangkul masyarakat sipil, lembaga riset kampus, dan pemerintah agar berperan aktif menangani masalah violent extremism di Indonesia (PPIM, 2018).

Buku ini berawal dengan sebuah penelitian yang dilakukan di 16 lokasi yang dianggap dapat mewakili untuk memotret fokus permasalahan yang dikaji, yakni persinggungan generasi milenial, pelajar SMA dan mahasiswa dengan Islamisme. Lokasi-lokasi tersebut adalah: Medan, Padang, Pekanbaru, Bogor, Bandung, Surakarta, Yogyakarta, Surabaya, Jember, Pontianak, Banjarmasin, Makassar, Palu, Ambon, Denpasar dan Mataram (halaman vi). 
Fokus buku ini adalah memetakan literatur keislaman yang beredar dan dibaca generasi milenial, khususnya pelajar SMA dan mahasiswa. Penelitian ini juga melihat tingkat keberterimaan literatur keislaman yang beraneka ragam dalam orientasi ideologis, genre, kecenderungan pendekatan, dan gaya di kalangan generasi milenial. Pekerjaan riset lapangan ini dilakukan selama tiga bulan. Sebelum menjadi buku, hasil penelitian ini telah diseminarkan di lima kota: Medan, Jakarta, Mataram, Banjarmasin dan Yogyakarta dengan mengundang beberapa narasumber (halaman vii). Penelitian dilakukan dengan memilih beberapa SMA, SMK dan MA, baik negeri maupun swasta, juga perguruan tinggi negeri, baik swasta maupun negeri, baik yang berada di bawah Kementerian Riset dan Pendidikan Tinggi maupun Kementerian Agama.

\section{MELANJUTKAN PENELITIAN}

Buku ini sesungguhnya adalah berupaya melanjutkan rintisan kajiankajian tentang literatur keislaman yang telah dilakukan (halaman 21). Salah satu yang mengemuka tentang rintisan kajian literatur keislaman adalah yang dilakukan oleh Watson (2005). Watson (2005: 191-203) memetakan penerbit buku Islam untuk melihat polarisasi komunitas Muslim Indonesia. Ia menyebutkan lima penerbit buku Islam dengan masing-masing segmen pembaca dan afiliasi ideologi keagamaannya, yakni (1) penerbit Mizan yang akhirnya lebih banyak mengusung paham keagamaan moderat; (2) Gema Insani Press (GIP) yang buku-buku terbitannya banyak menjadi rujukan bagi aktivis tarbiyah dalam jemaahjemaah pengajian di kampus-kampus. Penerbit ini juga menurutnya lebih sering memberikan "membela" terhadap ajaran Islam yang lebih literal; (3) Lembaga Kajian Islam dan Sosial (LKiS) yang kontras dengan GIP. Buku-buku terbitan
LKiS mengkhususkan pada pandangan Islam yang progresif dan dikaitkan dengan pemikiran progresif kaum muda NU. Buku pertama LKiS, yang berjudul Kiri Islam, menjadi simbol tersendiri untuk penerbit ini, yang hingga sekarang masih terus cetak ulang, pembacanya banyak berasal dari kalangan mahasiswa yang aktif di organisasi ekstra kampus; (4) Pustaka Al-Kautsar, yang dalam hal orientasi keagamaannya hampir sama dengan GIP. Diantara kebijakan penerbit ini adalah mengoreksi segala hal yang dianggap 'menyimpang;' (5) Khairul Bayan, penerbit kecil yang hampir sama juga dengan Pustaka Al-Kautsar. Penerbit ini sangat kontra dengan liberalisme dan sufisme. Watson tidak memeriksa bagaimana buku-buku tersebut dibaca dan diterima oleh pembaca. Analisisnya hanya berdasar pada penerbit buku. Tidak melihat bagaimana proses transmisi pengetahuan yang berada di dalam buku tersebut sehingga pesan-pesan di dalam buku diterima oleh pembaca.

Baru setelah itu muncul beberapa kajian tentang literatur keislaman yang mengembangkan kajian Watson tersebut. Misalnya Latief (2010) menemukan, bahwa bacaan yang digunakan para aktivis kampus kebanyakan adalah bukubuku yang digunakan dalam halaqah (pertemuan diskusi) salafi dan tarbiyah, yang mayoritas merupakan karya ulama Timur Tengah yang mencakup tiga aliran Islam yaitu: (1) salafi-purifications literatur, (2) literatur Islam umum, dan (3) politik yang berorientasi sastra.

Hal yang membedakan dan sebagai kelanjutan dari kajian-kajian yang sudah ada, buku ini tidak hanya terhenti pada buku-buku bacaan luar kelas dan majalah yang diasumsikan berpengaruh terhadap konstruksi pengetahuan dan ideologi keislaman generasi muda. Buku ini juga menganalisis buku-buku teks pelajaran atau mata kuliah Pendidikan Agama Islam yang dipakai dalam pembelajaran 
di kelas. Inilah yang menurut buku ini kerap kali diabaikan dalam studi-studi kesarjanaan tentang literatur keislaman. Padahal, buku teks pelajaran sangat penting untuk mengetahui daya penetrasi Islamisme ke dalam sistem pendidikan yang ada di Indonesia maupun caracara penyebaran dan tingkat kedalaman pengaruhnya di kalangan pelajar dan mahasiswa (halaman 21).

\section{PERSPEKTIF ISLAMISME}

Buku ini ditulis sebetulnya dalam rangka untuk membaca dinamika dan pergeseran Islamisme, terutama di kalangan anak muda. Hal ini dilakukan karena kebanyakan sarjana hanya memerhatikan dinamika ideologi gerakan Islam, sehingga mengabaikan hal yang lebih mendasar menyangkut faktor yang membentuk ideologi tersebut. Buku ini berargumen bahwa peran literatur keislaman dalam persemaian Islamisme di kalangan generasi milenial, khususnya pelajar dan mahasiswa, jelas tidak bisa diabaikan (halaman 18). Karena itu, jelas bahwa buku ini menggunakan perspektif Islamisme dalam menganalisis literatur keislaman yang ditemukan dalam penelitian.

Bassam Tibi-sarjana kajian Islam dan politik berdarah Damaskus dan kemudian menjadi guru besar di Universitas Gottingen Jerman-memiliki pandangan yang kurang positif terhadap "Islamisme." Menurutnya, Islamisme terkait tatanan politik, bukan iman, tetapi bukan semata politik, Islamisme adalah politik yang diagamasisasikan. Ia berpandangan bahwa Islamisme adalah contoh paling kuat dari fenomena global fundamentalisme religius (Tibi, 2016: 1).

Namun demikian, meskipun ada kesamaan, buku ini memiliki nada yang berbeda dengan pengertian Tibi tentang Islamisme. Setelah menguraikan beberapa uraian tentang konsep Islamisme dari beberapa sarjana, buku ini mengajukan sebuah pandangan bahwa Islamisme bukanlah berarti Islam yang identik dengan kekerasan seperti yang banyak dipersepsikan publik. Namun, Islamisme seperti agama itu sendiri, tidak kebal dengan manipulasi simbol agama yang berujung dengan tindakan kekerasan. Islamisme lebih merupakan aktivisme yang berkomitmen mewujudkan agenda politik tertentu dengan menggunakan simbol, doktrin, bahasa, gagasan dan ideologi Islam (halaman 13-14).

Kata kunci yang bisa menjadi sarana untuk lebih memahami Islamisme adalah agenda politik. Agenda politik pun memiliki pengertian yang sangat luas, mulai dari sekadar memperjuangkan aspirasi dan hak-hak politik hingga mengalahkan atau menjatuhkan rezim yang berkuasa. Caranya juga beragam, dari aksi-aksi kolektif untuk menyampaikan pendapat secara damai, demontrasi massal, membentuk partai politik, berpartisipasi dalam pemilihan umum, hingga gerakan bawah tanah dan teror. Dengan begitu, terkadang kekerasan menjadi salah satu cara untuk mewujudkan agenda politik Islamisme (halaman 14).

Namun, Islamisme bukanlah sebuah konsep yang statis, tetapi dinamis. Islamisme di Indonesia sekarang ini justru digerakan oleh Muslim urban dari kota-kota besar seperti Jakarta, Bogor, Bandung, Yogyakarta, dan Solo. Mereka bukan semata menginginkan untuk kembali kepada Islam klasik dan menentang modernitas. Namun justru seakan ingin merangkul keduanya. Salah satu agen penting Islamisme adalah kaum muda Muslim yang berperan aktif dalam penyelenggaraan aktivitas keagamaan, mobilitas politik, dan penggunaan simbol-simbol agama di ruang publik (halaman 69).

Melalui perspektif Islamisme, buku ini menemukam bahwa literatur 
Islamisme yang banyak beredar di kalangan generasi muda Muslim milenial secara umum dapat dikategorikan ke dalam tiga corak: keislaman ideologis, puritan dan kesalehan populer. Corak keislaman ideologis banyak ditemukan dalam literatur jihadi, Tahriri (Hizbut Tahrir) dan Tarbawi. Sementara ideide puritanisme banyak ditemukan di dalam literatur Salafi yang membuat teks bersanad sebagai standar dan paradigma purifikasi. Adapun ide kesalehan populer, atau kemudian disebut dengan Islamisme populer, banyak ditemukan dalam literatur Islamisme populer. Topiknya beragam seperti motivasi dan genre fiksi. Penulisnya pun beragam dari berbagai latar belakang organisasi dan ideologi Islamis (halaman 75).

Literatur tahriri (dengan gagasan revitalisasi khilafah) berhasil dalam skala yang lebih luas dibanding literatur jihadi (ideologi jihad) dalam menyebarkan pengaruhnya di kalangan pelajar dan mahasiswa. Literatur salafi juga berhasil mengembangkan pengaruhnya di kalangan pelajar dan mahasiswa, bahkan lebih menonjol dibandingkan literatur tahriri. Jika literatur tahriri, salafi dan tarbawi berhasil dalam beberapa tingkat mengambil perhatian sebagian pelajar dan mahasiswa, literatur jihadi tampaknya mengalami kegagalan signifikan (halaman 277).

Buku ini juga menemukan bahwa, dibandingkan literatur salafi, literatur tarbawi yang membawa misi menyebarkan ideologi Ikhwanul Muslimin, yang bercita-cita mengubah tatanan politik yang berlaku saat ini, berhasil mempengaruhi lebih luas dan mendalam di kalangan pelajar dan mahasiswa. Namun demikian, literatur keislaman yang mengusung tema-tema keseharian dan popular ("Islamisme popular") rupanya lebih mendapat tempat yang sangat penting di kalangan pelajar dan mahasiswa. Pengaruhnya paling luas dibandingkan dengan corak- corak literatur keislaman di atas. Hal ini antara lain karena meskipun disisipi oleh pesan-pesan ideologis, literatur Islamisme mengemas isi dengan ringan dan trendi sesuai dengan gaya anak muda, sekaligus menawarkan berbagai tuntutan praktis bagi Muslim untuk menjalani kehidupan. Beberapa literatur Islamisme populer dapat disebut sebagai berikut: La Tahzan, Udah Putusin Aja!, Yuk Berhijab, Ayat-ayat Cinta, dan Beyond the Inspiration (halaman 279).

Buku ini juga menggarisbawahi bahwa terjadi pergeseran literatur Islamisme Indonesia, yakni dari karyakarya terjemahan para ideolog Islamis seperti Sayyid Qutb, Hasan Al-Banna, Al-Maududi, Ali Syariati, Taqiyuddin An-Nabhani ke karya-karya yang mengapropriasi ide-ide para tokoh Islamis tersebut ke dalam konteks yang baru yang dihadapi masyarakat Indonesia. Jika di tahun 80-an dan 90-an, literatur-literatur Islamis yang memikat anak muda Muslim adalah literaturliteratur yang bercorak ideologis yang sarat dengan jargon "Islam adalah solusi" misalnya, literatur-literatur Islamis yang memikat hati generasi muda tahun 2000an atau generasi milenial adalah literatur keislaman yang bercorak motivasi, pengembangan diri, cerita dalam bentuk novel dan komik, selain juga ditampilkan dalam kemasan yang menarik dengan ragam ilustrasi (halaman 170).

Selain itu, kepanikan moral atau isu-isu moralitas dan tipe ideal anak muda Muslim masa kini juga menjadi tema yang banyak diangkat oleh literatur Islamisme baru ini. Isu kepanikan moral muncul dalam kasus isu Valentine Day, pergaulan remaja dan pakaian Muslimah. Isu kepanikan moral ini tampak dalam buku-buku Felix Siauw seperti Udah Putusin Aja! dan Yuk Berhijab, serta Salim A Fillah seperti Nikmatnya Pacaran setelah Menikah dan Agar Bidadari Cemburu Padamu (halaman 171). 


\section{LITERATUR ONLINE DAN KARAKTER MILENIAL: LUPUT DARI PERHATIAN}

Hal yang luput dari perhatian buku ini, atau setidaknya tidak diulas secara mendalam, adalah soal perkembangan literatur keislaman online. Memang ini bisa ditutupi dengan argumen bahwa bagaimanapun, literatur-literatur online yang tersedia tetap bersandarkan pada literatur-literatur yang tersedia secara tercetak. Literatur online ini bukan semata dalam pengertian buku elektronik (e-book), tetapi seluruh pengetahuan keagamaan yang tersedia secara online, baik melalui website yang dicari melalui mesin pencari google maupun yang tersebar melalui media sosial.

Tidak dapat dipungkiri bahwa perkembangan ide-ide Islamisme juga merambah secara online. Literaturliteratur Islamisme disebarkan secara online oleh sekelompok aktivis Islamisme, baik untuk menyampaikan sebuah opini terhadap sebuah permasalahan maupun sebagai wahana penggerakan massa. Wacana Islam disampaikan melalui teksteks online. Sebagaimana yang telah dikaji oleh Ahyar (2017: 435-468), terdapat gerakan Islam via internet, yang disebut dengan "clickitivism." Penelitian Ahyar ini dilakukan di Kota Surakarta, meskipun demikian tidak menutup kemungkinan terdapat juga di berbagai kota lainnya. Ia berargumen bahwa internet (khususnya media sosial) memiliki peran dalam menyebarkan informasi, baik yang berlanjut pada aksi nyata maupun pada sekadar bahan diskusi di kalangan internal aktivis. Hal yang penting dan terkait dengan penelitian kali ini adalah orang-orang yang terlibat di dalam aktivisme tersebut. Orang-orang yang terlibat dalam aktivisme tersebut adalah lulusan beberapa kampus ternama di kota Surakarta, dan kebanyakan tidak berlatar belakang pendidikan dalam kajian Islam.
Sepanjang buku ini generasi milenial selalu disebut, namun luput dari penjelasan. Padahal hal ini penting sebagai latar belakang subyek bahasan yang dikaji. Selain itu, karakter generasi milenial juga memberikan implikasi tersendiri dalam pemilihan fokus kajian. Mungkin inilah salah satu yang menyebabkan tidak begitu mendalamnya pembahasan mengenai literatur online, sebab salah satu ciri generasi milenial adalah selalu terhubung dengan internet.

Neil Howe dan William Strauss (2000) mendefinisikan generasi milenial sebagai mereka yang terlahir pada 1982 hingga kira-kira dua puluh tahun setelahnya. Cirinya adalah mereka dianggap sebagai native digital, tumbuh dalam masa dunia digital dan teknologi informasi yang berkembang canggih. Kedua, ketika belajar, generasi milenial lebih suka membaca PowerPoint daripada buku-buku tebal. Mereka merasa terbebani jika harus membaca buku tebal. Jikapun harus membaca buku yang tebal, maka yang dibaca adalah buku-buku novel yang disajikan dengan bahasa yang mudah. Uraian panjang tentang suatu pemikiran yang rumit sering kali dihindari, sebaliknya mereka lebih menyenangi kata-kata atau kutipan bijak yang memotivasi. Ketiga, generasi milenial sering kali merasa sibuk meskipun tidak jelas apa yang menyibukkan mereka. Keempat, generasi milenial juga mudah berpindah-pindah kerjaan dari satu tempat ke tempat lain. Kelima, generasi milenial terbiasa melakukan banyak hal dalam satu waktu (multitasking) meskipun dengan kurangnya pendalaman (Setowara, dkk., 2018: 199). Karena itu mereka akan selalu terhubung dengan dunia luar di satu sisi, tetapi juga cenderung pragmatis di sisi lain. Dengan penjelasan seperti ini seharusnya dapat menambah analisis tentang literatur keislaman milenial. 


\section{PENUTUP}

Ada beberapa hal yang belum diuraikan dalamulasan buku ini. Beberapa hal itu adalah tentang bagaimana menu bacaan Pendidikan Agama Islam di SMA dan Perguruan Tinggi, sirkulasi dan transmisi literatur keislaman, dinamika literatur keislaman di tingkat lokal, hingga soal keberadaan literatur-literatur yang menjadi tandingan (counter discourse) terhadap literatur Islamisme yang massif tersebar. Namun, secara garis besar, buku ini ingin menunjukkan bahwa literatur keislaman yang tersedia dan diakses generasi muda Muslim menunjukkan tipe pemikiran Islam seperti apa yang digandrungi generasi ini.
Sayangnya, buku ini tidak dilengkapi oleh indeks, baik indeks nama tokoh maupun subyek atau topik. Keberadaan indeks ini penting, karena dapat memudahkan pembaca untuk menelusuri informasi yang ada di dalam buku. Namun, kekurangan ini tidak menutup sumbangsihnya yang penting pada kajian literatur Islam anak muda di Indonesia. Terbukti dalam waktu kurang dari setahun buku ini sudah cetak ulang. Ke depan ketika akan cetak ulang, beberapa kekurangan bisa dilengkapi demi kesempurnaan karya penting ini.

\section{DAFTAR ACUAN}

Ahyar, Muzayyin. 2017. Islamic Clicktivism: Internet, Democarcy and Contemporary Islamic Activism in Surakarta. Studia Islamika Volume 24, Nomor 3: 435-468.

Bamualim, Chaider S, dkk. 2018. Kaum Muda Muslim Milenial: Konservatisme, Hibridasi Identitas, dan Tantangan Radikalisme. Tangerang Selatan: Center for Study of Religion and Culture.

Bowen, John R. 1993. Muslim through Discourse: Religion and Ritual in Gayo Society. Princeton, New Jersey: Princeton University Press.

Dhuhri, Saifuddin. 2016. The Text of Conservatism: The Role of 'Abbas Ahl Sunnah wal Jamaah in Underpinning Achenese Current Religious Violence. Studia Islamika Volume 23, Nomor 1: 29-59.

Hayik, Rawia. 2015. Addresing Religious Diversity through Children Literature: An "English as Foreign Language" Classroom in Israel. International Journal of Multicultural Education Volume 17, Nomor 2: 92-106.

Howe, Neil, William Strauss. 2000. Millenials Rising: The Next Great Generation. New York: Vintage Book.

Latief, Hilman. 2010. Youth, Mosque, and Islamic Activism: Islamic Sources Books in University-Based Halaqah. Kultur: The Indonesian Journal for Muslim Culture Volume 5, Nomor 1: 63-88.

Pusat Pengkajian Islam dan Masyarakat. 2018. Ringkasan Eksekutif Program CONVEY Indonesia. Tangerang Selatan: Pusat Pengkajian Islam dan Masyarakat (PPIM).

Rackley, Eric D. “Motivation for Religious Literacy Practices of Religious Youth: Eximining the Practices of Letter day Saint and Methodist Youth in One Community." Disertasi Doktoral di Universitas Michigan, 2010. 
Setowara, Subhan, dkk. 2018. Muslim Milenial: Catatan dan Kisah Wow Muslim Zaman Now. Bandung: Mizan.

Tibi, Bassam. 2016. Islam dan Islamisme. Bandung: Mizan

Watson, C.W. 2005. Islamic Books and Their Publishers: Notes on the Contemporary Indonesian Scenes. Journal of Islamic Studies Volume 16, Nomor 2: 177-210. 